\title{
Evacuation Modelling in New Zealand the Result of An Online Survey
}

\author{
Ruggiero Lovrelio*, Ed Claraidge and Phil Jackson \\ Massey University, New Zealand \\ *Corresponding author: Ruggiero Lovrelio, Massey University, New Zealand
}

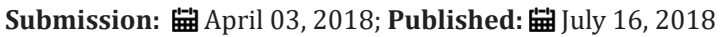

\section{Introduction}

Enhancing building fire safety is a fundamental task to reduce the impact of those disasters on occupants. This has been achieved around the word by introducing a performance-based approach which allow designer and building manager to assess how a building can respond from a fire and evacuation point of view.

This change has occurred also in New Zealand. In fact, fire engineering has experienced major changes in New Zealand in the last five years with the introduction of the 2012 edition of the Building Code [1]. The C/VM2 Verification Method [2] represents a compromise between a prescriptive approach and a novel performance-based approach by providing several prescriptive inputs for fire and evacuation modelling and provide a novel 'Framework for Fire Safety Design'. The performance approach relies on the comparison ASET and RSET, where ASET stands for Available Safe Egress Time while RSET stands for Required Safe Egress Time [3]. As such, fire engineers are asked to predict and model several fire and evacuation scenarios to ensure that the RSET is greater than the ASET.

To date, fire engineering can use several computational tools to simulate fire and smoke dynamics as well as the evacuation process. According to an existing survey [4], it was shown that FDS computational fluid dynamics program by NIST and BRANZ's B-RISK zone model were the most popular tools to estimate ASET in New Zealand. The commentary document of C/VM2 provided to support C/VM2 specifically describes the use of FDS and BRANZFIRE as the basis for a number of exemplar scenarios. In contrast, no computer evacuation model is discussed. Moreover, there is no available survey describing which evacuation model are used in New Zealand [5].

Through this short article we present the final results of a survey carried out in the 2017 to investigate the awareness and use of the existing computational evacuation models.

\section{Survey}

We developed a closed response survey to quantify which evacuation model's participants were familiar with and which model's participants have been using through their careers. This survey has been disseminated with the help of the Fire Protection Association NZ, the Institution of Fire Engineers New Zealand and social networks such as LinkedIn and Twitter since June 2017 and through FireNZ 2017 conference.

\section{Results}

To date 93 participants from the NZ fire engineering community have completed this survey. Most of them are fire engineers working as fire consultants or designers (71\%) while the remaining ones are engineers, fire officers and academics. The average work experience in fire safety of those participants is ten years, while the average years of experience in performance-based design and evacuation models is six years and five years respectively.

According to this sample, the most known evacuation model in New Zealand is Pathfinder (67\%) followed by FDS+Evac (63\%), Exodus and STEPS (50\%), Simulex (45\%) and EvacuatioNZ (42\%). While all the remaining models (i.e. Legion, Mass Motion, VISSIM, PedGo) are below $40 \%$. In line with these statistics the most used model is Pathfinder (64\%) followed by FDS+Evac (40\%), EvacuatioNZ and Simulex (24\%), STEPS (18\%) and Exodus (16\%). Finally, the results indicate that the most favourite model is still Pathfinder (58\%) followed by FDS+Evac (20\%) and EvacuatioNZ $(10 \%)$. It is worth clarifying that those statistics do not add up to $100 \%$ as many participants stated to be aware and that they have used more than one model through their careers. A summary of these statistics is illustrated in Figure 1.

From the awareness viewpoint, the proposed results show many similarities with those from an international survey carried 
out by Ronchi and Kinsey [6] in 2011, who identify many of the same models as the most known and used models around the world as illustrated in Figure 2. The only difference is the awareness and use of EvacuatioNZ which is not as popular internationally as it is in New Zealand. From the use point of view, the use of evacuation models in New Zealand differs from other countries.

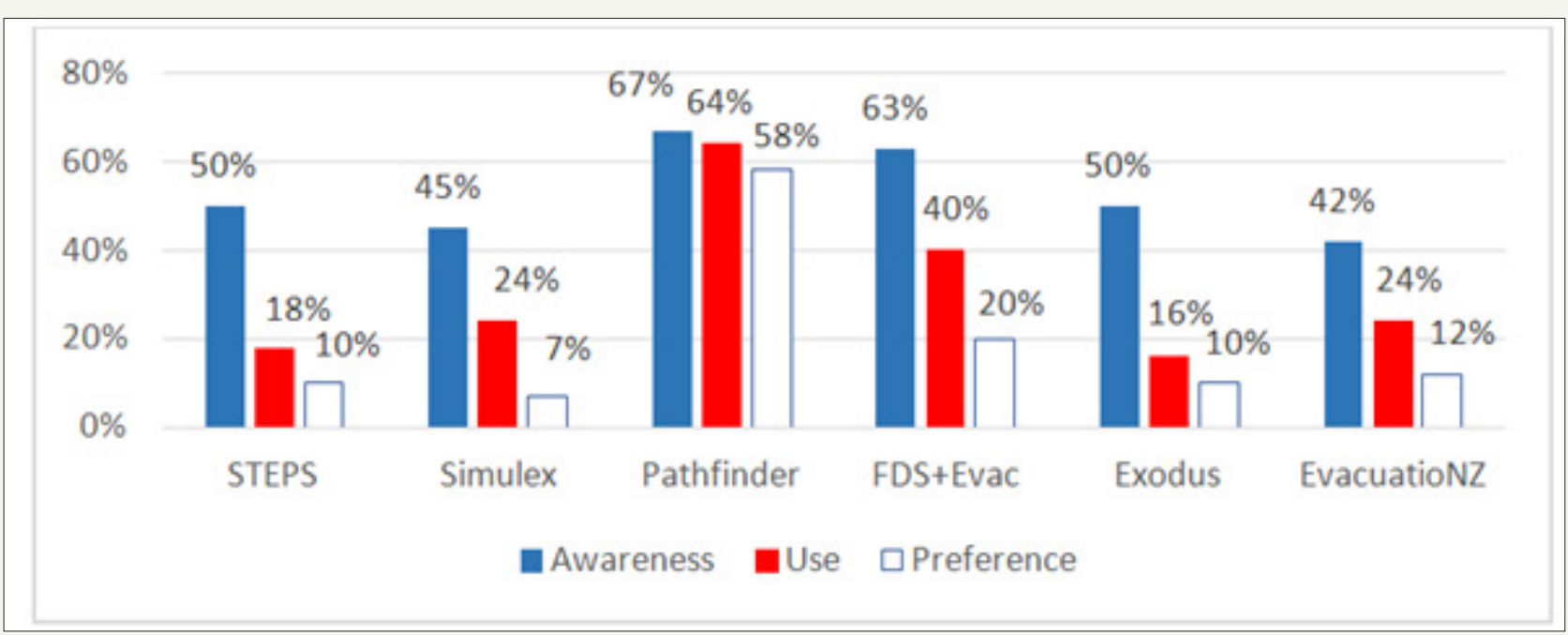

Figure 1: Percentages of the awareness, use and preference of evacuation models in New Zealand.

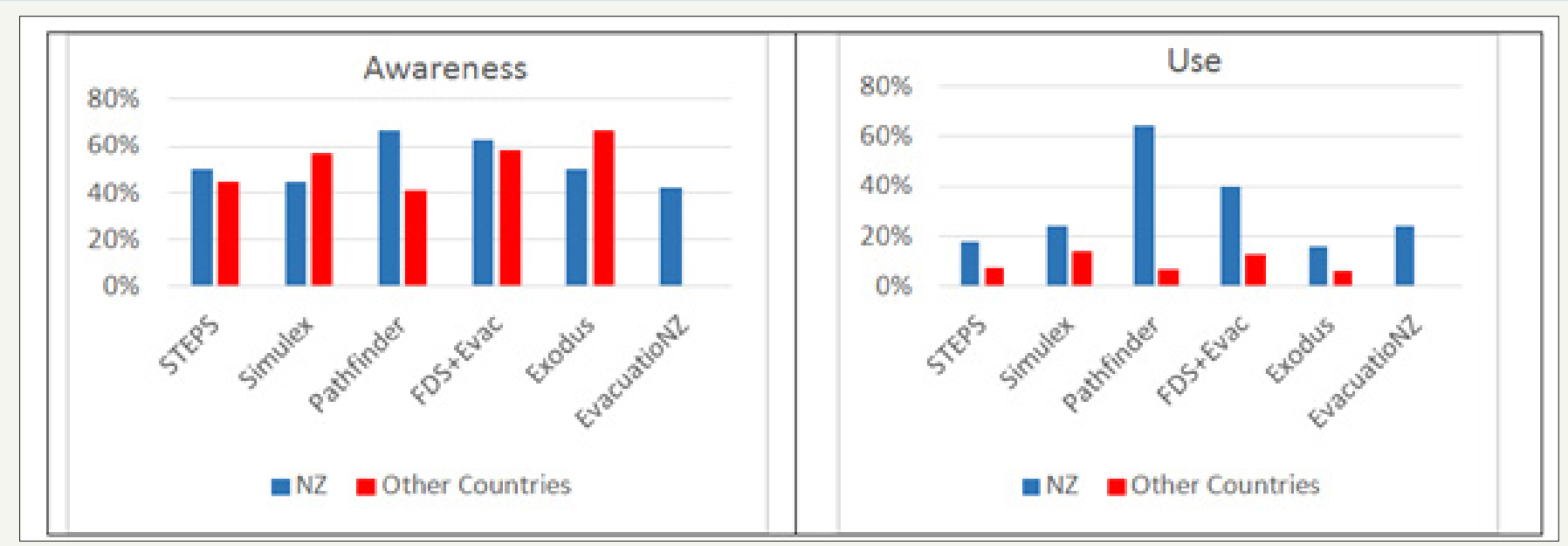

Figure 2: Comparison of the awareness and use of evacuation models in New Zealand and other countries.

Finally, these results indicate that the majority of the participants are not aware of many of the other computational evacuation models which have been developed by research groups and companies over the past 20 years but are not mentioned in this article. This lack of awareness could inhibit informed model selection as modellers are then not aware of the capabilities of all the available evacuation models [6]. Therefore, this survey identifies the need for a platform to provide updated information about all of the existing evacuation models, the behavioural assumptions or statements underpinning those models and the implemented behavioural sub-models for the pre-evacuation decision making, exit and route choices [10-17].

\section{Acknowledgement}

The authors thank Michael Spearpoint (Olsson Fire \& Risk) and Steve Gwynne (National Research Council Canada) for reviewing this article.

\section{References}

1. International Atomic Energy Agency (2010) Environmental Impact Assessment of Nuclear Desalination. IAEATECDOC- 1642, IAEA, Vienna, Austria, pp. 140.

2. AMTA (2007) Water Desalination Processes.

3. World Water Vision Commission Report (2000) A Water Secure World, World Water Forum. The Hague, Netherlands. 
4. IAEA (2000) Status of Non-Electric Nuclear Heat Applications: Technology and Safety. IAEA-TECDOC-1184, Vienna, Austria, pp. 296.

5. IAEA (1997) Experience gained in the operation and maintenance of the nuclear desalination plant in Aktau, Kazakhstan. Nuclear Desalination of Sea Water IAEA, Vienna Austria, pp. 1-576.

6. (2000) Examining the Economics of Seawater Desalination Using the DEEP Code. IAEATECDOC- 1186, IAEA, Vienna, Austria, pp. 88

7. Wangnick K (2001) Present status of thermal seawater desalination techniques. IDA Journal 10: 1.

8. International Atomic Energy Agency (1990) Use of Nuclear Reactors for Seawater Desalination. IAEA-TECDOC-574, Vienna, Austria, pp. 212.

9. International Atomic Energy Agency (1992) Technical and Economic Evaluation of Potable Water Production through Desalination of Seawater by Using Nuclear Energy and Other Means, IAEA-TECDOC666, Vienna, Austria, pp. 148.

10. International Atomic Energy Agency (1997) Nuclear Desalination of Sea Water. (Proc. Conf. Taejon, 1997), IAEA, Vienna, Austria.

11. Doval A, Masriera N (1999) Analysis of desalination system models relevant for the safety evaluation of a nuclear desalination plant. IDA World Congress on Desalination and Water Reuse, San Diego, California, USA.
12. Chang MH, Sim SK, Hwang YD (1999) SMART-An Advanced Small integral PWR for Nuclear Desalination and Power Generation. Global '99-International Conference on Future Nuclear Systems, Jackson Hole, Wyoming, USA.

13. Bae KH, Kim HC, Chang MH, Sim SK (2001) Safety Evaluation of the Inherent and Passive Safety Features of the SMART Design. Annals of Nuclear Energy 2: 333-349.

14. Chang HJ, Yeo W (2002) Advanced Design Features Adopted in SMART, IAEA-SR- 218/28. International Seminar on Status and Prospects for Small and Medium Size Reactors, Cairo, Egypt, 2001, IAEA, Vienna Austria, pp. 134.

15. International Atomic Energy Agency (2000) Introduction of Nuclear Desalination: A Guidebook. Technical Reports Series No. 400, IAEA, Vienna, Austria, pp. 291.

16. International Atomic Energy Agency (2000) Guidance for Preparing User Requirements Documents for Small and Medium Reactors and their Application. IAEATECDOC- 1167, Vienna, Austria, pp. 102.

17. International Atomic Energy Agency (2001) Safety Aspects of Nuclear Plants Coupled with Seawater Desalination and/or Other Heat Utilization Units, Vienna, Austria, pp. 88.
Creative Commons Attribution 4.0 International License

For possible submissions Click Here

\section{Submit Article}

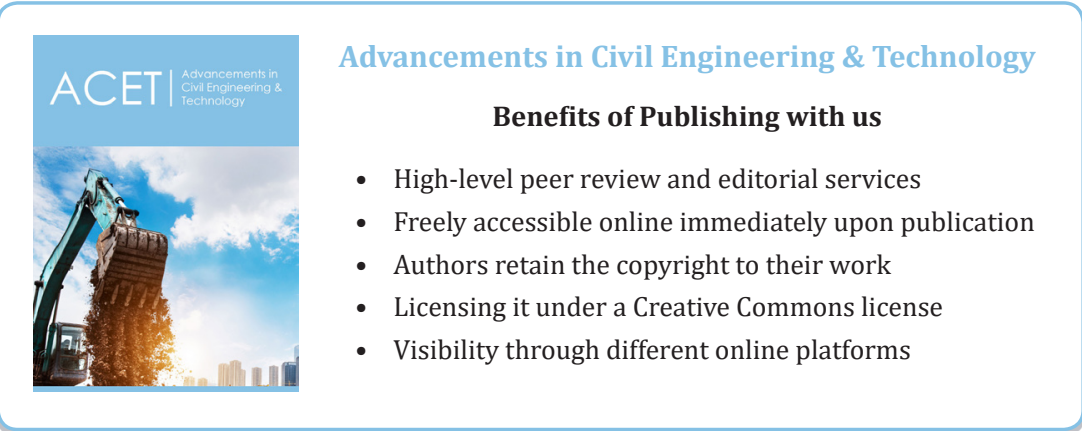

